\title{
Functional Role of Parkin against Oxidative Stress in Neural Cells
}

\author{
Minyoung Hwang ${ }^{1}$, Ja-Myong Lee ${ }^{1}$, Younghwa Kim², Dongho Geum ${ }^{1}$ \\ ${ }^{1}$ Department of Biomedical Sciences, Korea University College of Medicine, Seoul; ${ }^{2}$ Department of Emergency Medical \\ Technology, Kyungil University College of Nursing and Public Health, Gyeongsan, Korea
}

Background: Parkinson disease (PD) is caused by selective cell death of dopaminergic neurons in the substantia nigra. An early onset form of $\mathrm{PD}$, autosomal recessive juvenile parkinsonism has been associated with a mutation in the parkin gene. The function of parkin is known to remove misfolding proteins and protect cell death. We aimed to investigate the role of parkin against oxidative stress in neuronal cells.

Methods: Parkin knockout embryonic stem cells (PKO ES cells) were differentiated into neurons by adherent monolayer culture method. Oxidative stress was induced by the treatment of 1-methyl-4-phenylpyridinium (MPP ${ }^{+}$) in neurons derived from wild type and PKO ES cells, and cell viability was examined by MTT assay. After exposure to MPP ${ }^{+}$, Tuj1-positive cell population was compared between PKO and wild type cells by fluorescence activated cell sorter (FACS) analysis. The activated caspase3 protein level was also measured by Western blot analysis, FACS and immunocytochemistry.

Results: There was no difference in the efficiency of neuronal differentiation between wild type and PKO ES cells. After exposure to $\mathrm{MPP}^{+}$, no significant differences were found in cell viability and Tuj1-positive cell population between the two groups determined by MTT assay and FACS analysis, respectively. The activated caspase3 protein levels examined by Western blot analysis, FACS and immunocytochemistry were not changed in PKO cells compared with those of wild type cells after MPP ${ }^{+}$treatment.

Conclusion: These results suggest that PKO neuronal cells including dopaminergic neurons are not sensitive to caspase3-dependent cell death pathway during the response against $\mathrm{MPP}^{+}$-induced oxidative stress.

Keywords: Parkin; Dopaminergic neurons; Oxidative stress; Cell death; Embryonic stem cells

\section{INTRODUCTION}

Neurodegenerative diseases, such as Alzheimer disease, Par- kinson disease (PD), Huntington disease, and amyotrophic lateral sclerosis are characterized by the progressive loss of specific neural cells, and are associated with protein aggregation
Received: 27 July 2013, Accepted: 11 October 2013

Corresponding authors:

Younghwa Kim

Department of Emergency Medical Technology, Kyungil University College of Nursing and Public Health, 50 Gamasil-gil, Hayang-eup, Gyeongsan 712-701, Korea

Tel: +82-53-600-5681, Fax: +82-53-600-5681, E-mail: yhkim01@kiu.ac.kr

\section{Copyright $\odot 2014$ Korean Endocrine Society}

This is an Open Access article distributed under the terms of the Creative Commons Attribution Non-Commercial License (http://creativecommons.org/ licenses/by-nc/3.0/) which permits unrestricted non-commercial use, distribution, and reproduction in any medium, provided the original work is properly cited.

Dongho Geum

Department of Biomedical Sciences, Korea University College of Medicine,

73 Inchon-ro, Seongbuk-gu, Seoul 136-705, Korea

Tel: +82-2-2286-1091, Fax: +82-2-924-6324, E-mail: geumd@korea.ac.kr 
and accumulation [1,2]. Recently, it has been reported that oxidative stress might be involved in the dysfunction or death of neural cells that contributes to the pathogenesis of neurodegenerative diseases [3-6]. Oxidative stress is the result of unregulated production of reactive oxygen species, which lead to impaired cellular function through oxidative damage of lipids, proteins, and DNA [7].

PD is one of the most common neurodegenerative diseases, which is caused by selective cell death of dopaminergic neurons in the substantia nigra. Parkin is a 465 amino acid protein that contains two really interesting new gene (RING) finger domains and one in between RING domain that serves as an E3 ubiquitin ligase. Parkin functions to remove misfolded proteins and protect against cell death [8]. Mitochondrial dysfunction and oxidative damage also have been reported in parkin null mice [9], which suggests a protective role of parkin against oxidative stress. Recently, parkin and its interaction with PTEN induced putative kinase 1 have been shown to participate in the maintenance of mitochondrial function [10-12].

To determine whether parkin is associated with neuronal cell death caused by oxidative stress, parkin knockout embryonic stem cells (PKO ES cells) were used. PKO ES cells have the potential to differentiate into neuronal cells including dopaminergic neurons. In vitro, this system more closely reflects neuronal cells than established cell lines, such as SH-SY5Y, PC12, and NM9D. 1-Methyl-4-phenylpyridinium (MPP ${ }^{+}$) was used as an oxidative stressor, which is well known to induce cellular oxidative stress and PD-like symptoms.

\section{METHODS}

\section{Maintenance and differentiation of ES cells}

PKO ES cells were generated by deleting exon 2 of the parkin gene (unpublished data), and was provided by Dr. Richard Palmiter at University of Washington. Wild-type (WT) and PKO ES cells were maintained on mouse embryonic fibroblast feeder cells with leukemia inhibitory factor $(1,000 \mathrm{U} / \mathrm{mL}$, Chemicon, Temecula, CA, USA) in ES cell medium consisting of Dulbecco's modified Eagle's medium supplemented with $15 \%$ fetal bovine serum, $100 \mathrm{mM}$ nonessential amino acid, $0.5 \%$ antibiotics, and $0.55 \mathrm{mM}$ 2-mercaptoethanol, at $37^{\circ} \mathrm{C}$ in a $5 \%$ $\mathrm{CO}_{2}$. The adherent monolayer culture method was used for the differentiation of ES cells into neural cells as previously described without any modifications [13].

\section{Reverse-transcriptional polymerase chain reaction}

Total RNA was isolated using a ToTALLY RNA kit (Ambion, Austin, TX, USA). One microgram of the RNA template was reverse-transcribed using a Transcript First Strand cDNA Synthesis kit (Roche Diagnostics, Basel, Switzerland) according to the manufacturer's guidance. Subsequently, a $2 \mu \mathrm{L}$ aliquot of each sample was subjected to real-time polymerase chain reaction (PCR) in a $20 \mu \mathrm{L}$ reaction mixture containing $4 \mathrm{mM}$ $\mathrm{MgCl}_{2}, 10$ pmol of upstream and downstream primers, and 2 $\mu \mathrm{L}$ of 10X Light Cycler Fast Start DNA Master SYBR Green 1 (Roche Diagnostics). Data were analyzed with Light Cycler software version 3.5 (Roche Diagnostics). The following primer sets were chosen for real-time PCR analyses.

Glyceraldehyde 3-phosphate dehydrogenase: 5'-GTGTTCCTACCCCCAATGTG-3'; 5'-TGTGAGGGAGATG- CTCAGTG-3' (400 bp), Nurr1: 5'-CGGTTTCAGAAGTGCCTAGC-3'; 5'-CTGGGTTGGACCTGTATGCT-3' (420 bp), Pitx3: 5'-ACAAAGTGGAAC- CCCTATGAG-3'; 5'-TTCTTGGCCAATCTGTAGGA-3' (255 bp), tyrosine hydroxylase (TH): 5'-TTGGCTGACCGCACATTTG-3'; 5'-ACGAGAGGCATAGTTCCTGAGC-3' (336 bp), aromatic L-amino acid decarboxylase (AADC): 5'-AGAAGAGGCAAGGAGATGGTGG-3'; 5'-AAGCGAAGAAAT- AGGGAC-TCTGC-3' (214 bp), dopamine receptor 2 (D2R): 5'-CCTT- CATCGTCACCCTGCTGG-3'; 5'-CTCCATTTCCAGCTCCTGAG-3' (245 bp/158 bp).

\section{Immunocytochemistry}

Cells were fixed with $4 \%$ paraformaldehyde in phosphate buffered saline (PBS) for 20 minutes at room temperature, and treated with $0.3 \%$ Triton X-100 in 10\% normal goat serum for 45 minutes. Cells were incubated at $4^{\circ} \mathrm{C}$ overnight with primary antibodies in blocking solution. After washing with PBS containing $0.1 \%$ bovine serum albumin three times, cells were incubated at room temperature for 1 hour with fluorescently labeled secondary antibodies. Subsequently, cells were washed three times with PBS containing $0.1 \%$ bovine serum albumin, and then washed with PBS containing 4, 6-diamidino-2-phenylindole (DAPI) for nuclear staining. After nuclear staining, cells were washed once more with distilled water, then mounted with CRYSTAL/MOUNT (Biomeda Corp., Foster City, CA, USA). The following primary antibodies were used. MAP2 (1:500, Chemicon), Tuj1 (1:500, Chemicon), TH (1:500, Chemicon), and cleaved caspase 3 (1:250, cell signaling). 


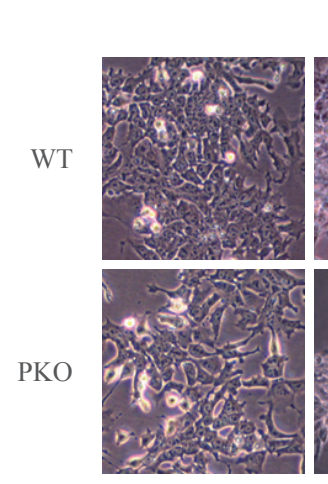

Day 0
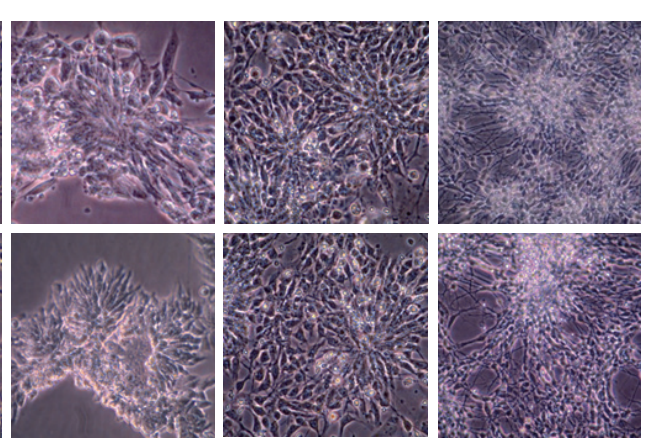

Day 10

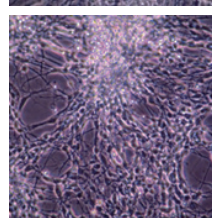

Day 15
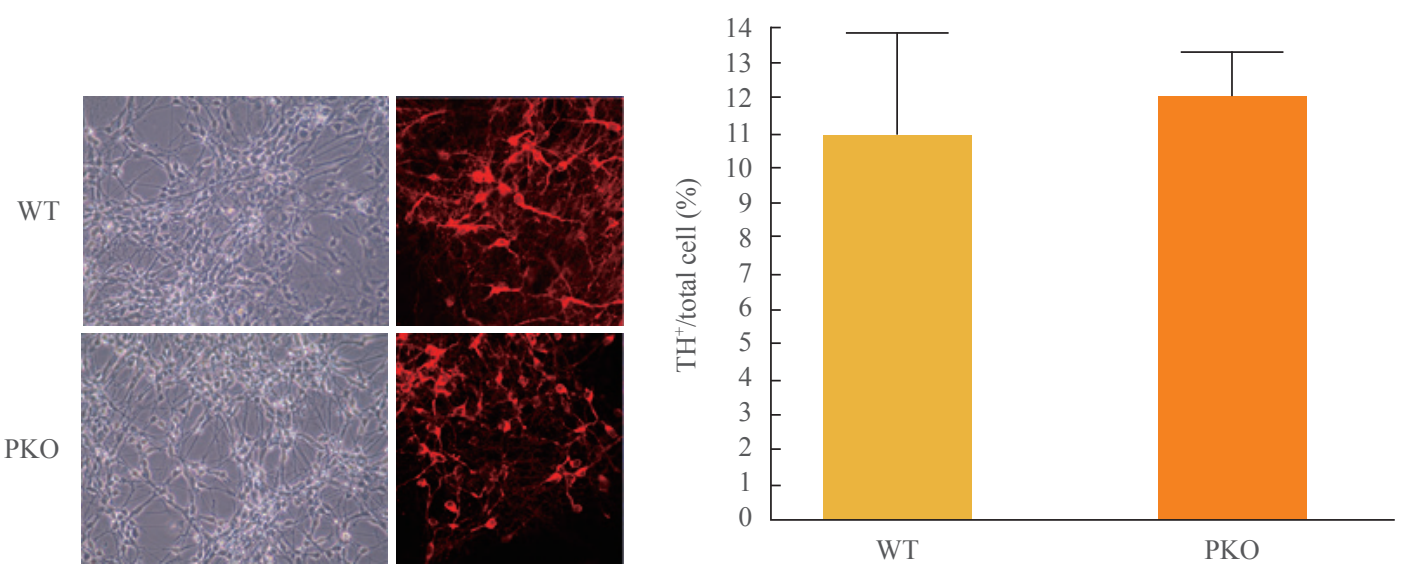

B
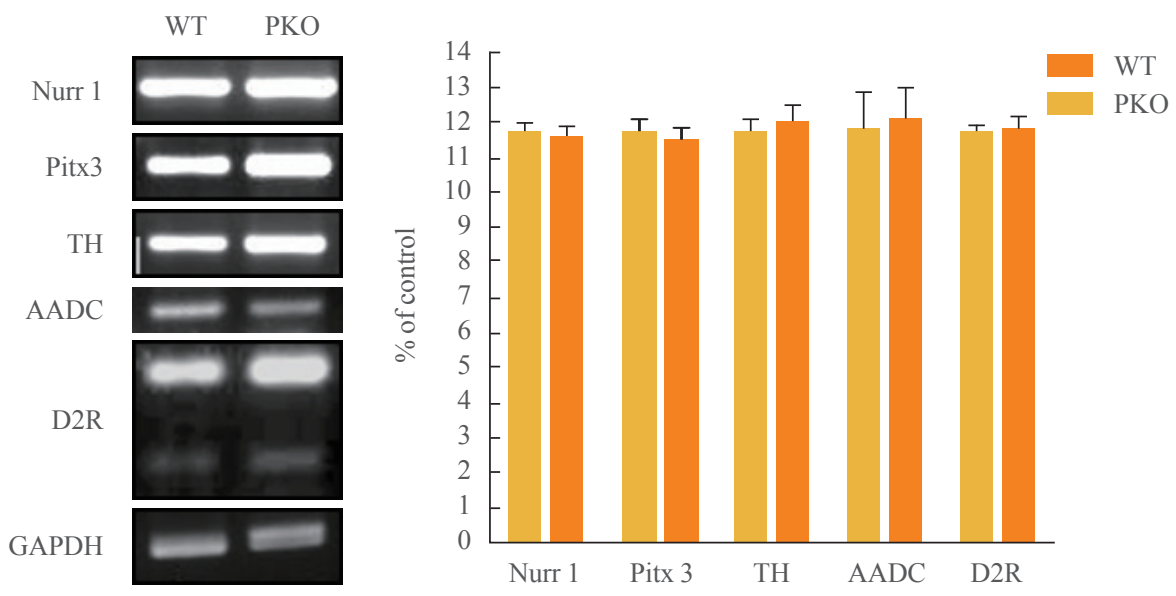

C

Fig. 1. Induction of dopaminergic neurons from wild-type (WT) and parkin knockout embryonic stem (PKO ES) cells by the adherent monolayer culture method. (A) Induction of neural cells from WT and PKO ES cells by the adherent monolayer method. Representative images were taken $0,5,10$, and 15 days after differentiation. Immunocytochemistry shows MAP2-positive mature neural cells, and 6-diamidino-2-phenylindole (DAPI) was used for nuclear staining. (B) Expression of tyrosine hydroxylase (TH) 15 days after differentiation. $\mathrm{TH}^{+}$neurons were analyzed by immunocytochemistry with an anti- $\mathrm{TH}$ antibody 15 days after differentiation. The $10 \%$ to $12 \%$ of cells were identified as TH-positive cells. (C) Reverse-transcriptional polymerase chain reaction analysis of dopaminergic neuron markers, such as Nurr1, TH, Pitx3, aromatic L-amino acid decarboxylase (AADC), and dopamine receptor 2 (D2R) at 15 days after differentiation. Glyceraldehyde 3-phosphate dehydrogenase (GAPDH) was used as an internal control. Data are expressed as mean \pm SEM $(n=3$ per group). Statistical analysis was performed by Student $t$ test. No significant differences in dopaminergic neuron marker expression were observed between WT and PKO cells. 


\section{Fluorescence-activated cell sorting}

WT and PKO ES cells were differentiated into neural cells for 12 days. Subsequently, cells were treated with or without $\mathrm{MPP}^{+}$(1 mM, Sigma, St. Louis, MO, USA) for 24 hours. Cells were harvested using $0.25 \%$ trypsin/ethylenediaminetetraacetic acid (Invitrogen, Carlsbad, CA, USA) containing DNase I (4 U/mL, Roche Diagnostics), and gently dissociated into a single-cell suspension. Then, cells were fixed and treated using a Cytofix/Cytoperm kit (BD Pharmingen, San Diego, CA, USA) according to the manufacturer's guidelines. Primary antibodies were added and incubated for 1 hour, and cells were then washed, incubated with Alexa Fluor 488 and/or 594 fluorescent secondary antibodies for 30 minutes, and subsequently washed. Fluorescence-activated cell sorting (FACS) was performed using a FACSAria cell sorter and FACSDiva software (BD Biosciences, San Jose, CA, USA). All FACS experiments were repeated at least three times.

\section{MTT assay}

ES cells $\left(6 \times 10^{2}\right.$ cells/well $)$ were seeded onto 12 -well plates, differentiated into neural cells for 12 days, and then treated with $\operatorname{MPP}^{+}(0,100,500,750,100,1,250$, and 1,500 $\mu \mathrm{M}$, Sigma) for 24 hours. Next, 3-(4,5-Dimethylthiazol-2-yl)-2,5-diphenyltetra- zolium bromide solution $(0.5 \mathrm{~g} / \mathrm{L})$ was added into each well and incubated at $37^{\circ} \mathrm{C}$ for 2 hours. Supernatants were removed and formazan crystals were dissolved in dimethylsulfoxide. Finally, optical density was determined at $570 \mathrm{~nm}$ by a SPECTRA max Plus (Molecular Devices, Sunnyvale, CA, USA).

\section{Western blot analysis}

To analyze the cell signaling pathways, Western blot analysis was performed. ES cells were differentiated into neural cells on $60 \mathrm{~mm}$ dishes and were treated with or without $1 \mathrm{mM} \mathrm{MPP}^{+}$ for 24 hours. Following treatment, the media were aspirated and the cells were washed twice in ice-cold PBS and suspended in $100 \mu \mathrm{L}$ of lysis buffer. The samples were then heated for 5 minutes at $95^{\circ} \mathrm{C}$, and centrifuged for 5 minutes. The quantitative analysis of protein was carried out via bicinchoninic acid assay. The samples were separated on sodium dodecyl sulfate polyacrylamide gel electrophoresis (8\%) gels, and transferred to nitro cellulose membranes. The blots were incubated with $5 \%$ skim milk at room temperature for 1 hour. Next, the blots were incubated overnight at $4^{\circ} \mathrm{C}$ with primary antibodies, and then washed three times in Tris-buffered saline/ $0.1 \%$ Tween 20 prior to 1 hour of probing with horseradish peroxidase-conju- gated secondary antibodies at room temperature. The blots were then visualized via enhanced chemiluminescence (Amersham Biosciences, Buckinghamshire, UK). In some cases, the blots were stripped and reprobed using other antibodies.

\section{Data analysis}

Data are expressed as means \pm SEM. Statistic analyses were conducted using SigmaStat (SPSS Inc., Chicago, IL, USA). $P$ values of $<0.05$ were considered statistically significant.

\section{RESULTS}

\section{Differentiation of PKO and WT ES cells into neural cells} by adherent monolayer culture method

To examine differences in efficiency of neural differentiation, WT and PKO ES cells were differentiated into neurons by the adherent monolayer culture method. Morphological changes were observed during a differentiation period, and immunocytochemistry was performed with MAP2, a mature neuron marker. There were no differences in the morphology or differentiation of MAP2-positive cells between WT and PKO cells (Fig. 1A). Specifically, the efficiency of neural differentiation into dopaminergic neurons showed no difference between WT and PKO ES cells, as determined by immunocytochemistry with TH, a dopaminergic neuron marker (Fig. 1B). Real-time RT-PCR analysis with dopaminergic neuron markers such as Nurr1, Pitx3, AADC, TH, and D2R also showed no difference

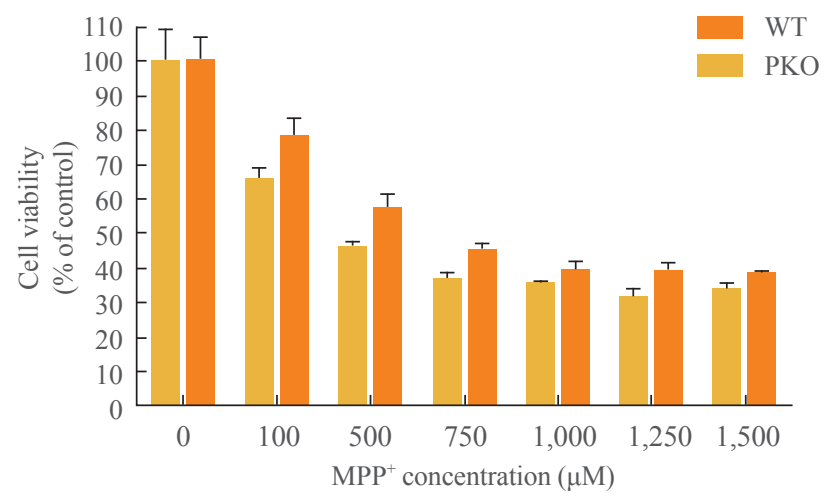

Fig. 2. Cell viability analysis after treatment with 1-methyl4-phenylpyridinium $\left(\mathrm{MPP}^{+}\right)$by MTT assay. $\mathrm{MPP}^{+}$was treated at various concentrations $(0,100,500,750,1,000,1,250$, and 1,500 $\mu \mathrm{M})$ for 24 hours, at 15 days after differentiation. MTT assay was performed for viability of differentiated cells. Data are expressed as mean $\pm \operatorname{SEM}$ ( $n=6$ per group). Statistical analysis was performed by two-way analysis of variance. No significant differences in the $\mathrm{MPP}^{+}$susceptibility were observed between wild-type (WT) and parkin knockout (PKO) cells. 

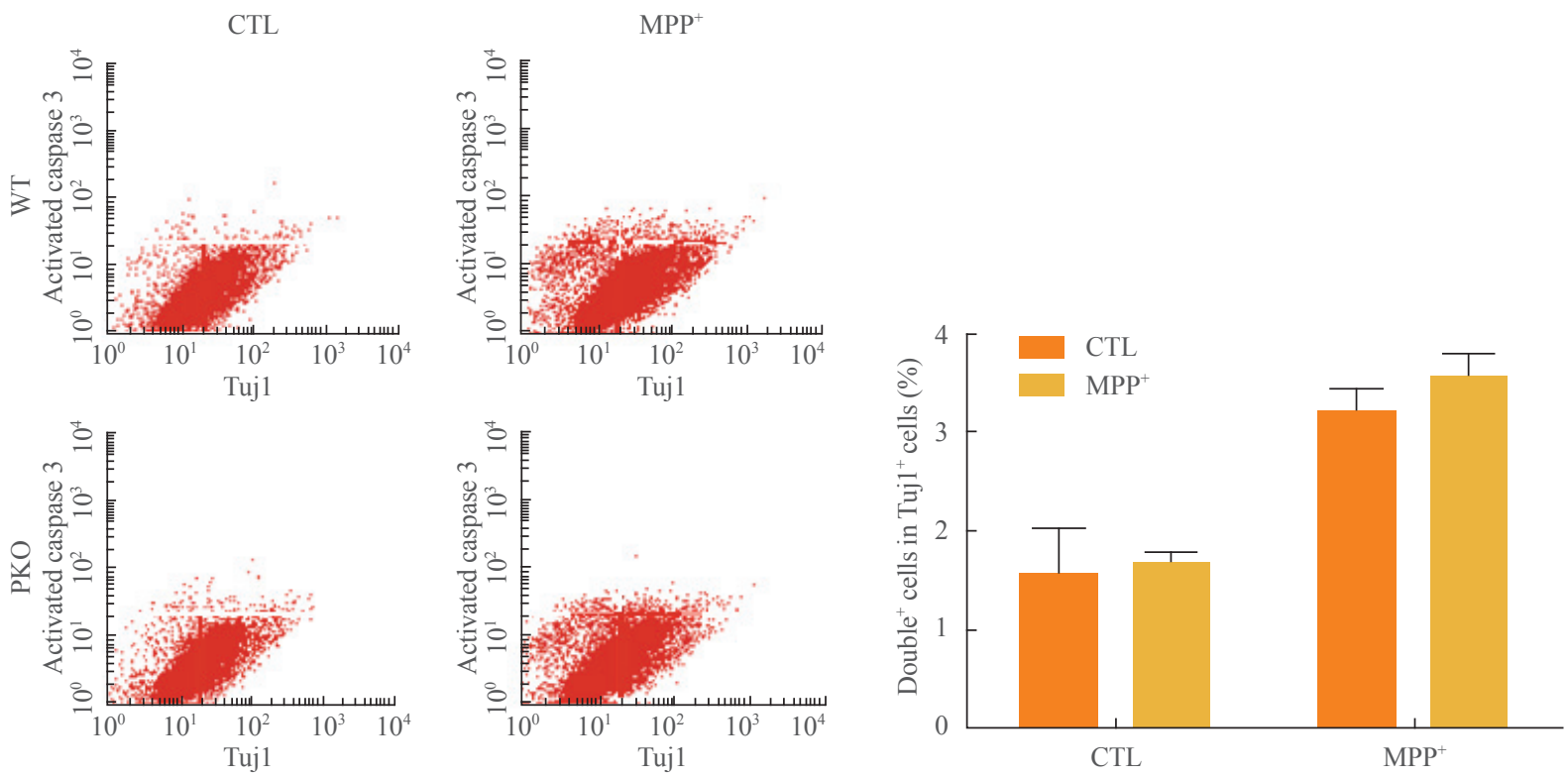

A

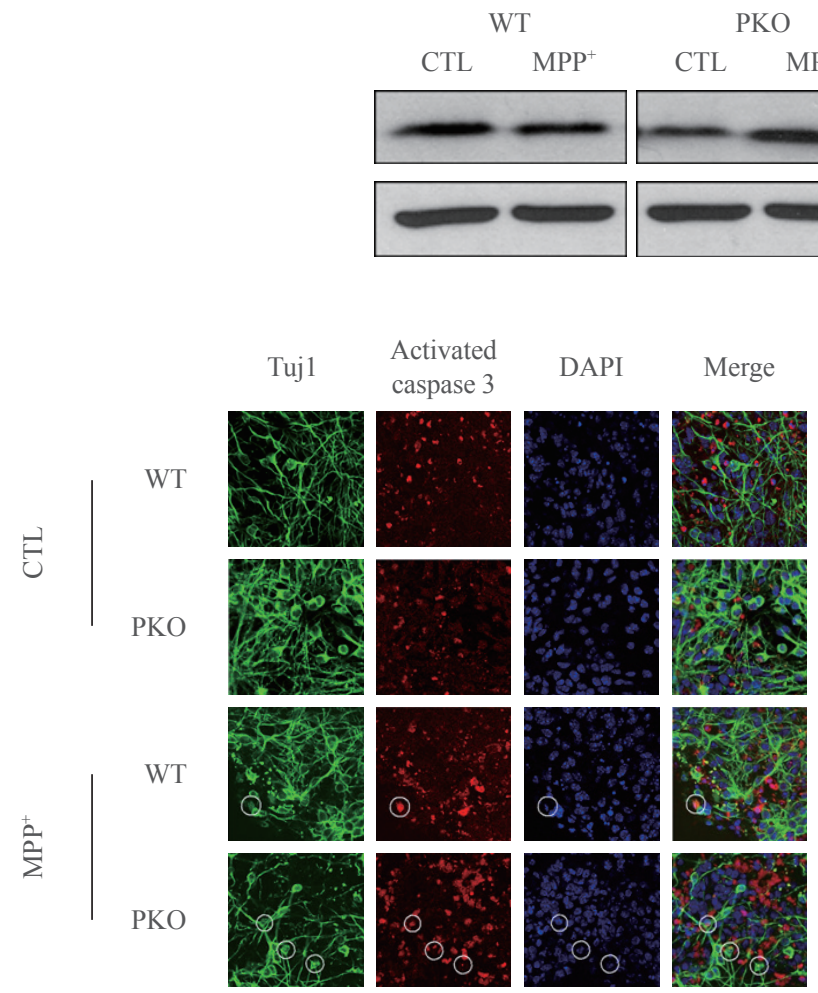

\section{Activated caspase 3 \\ $\beta$-Actin}

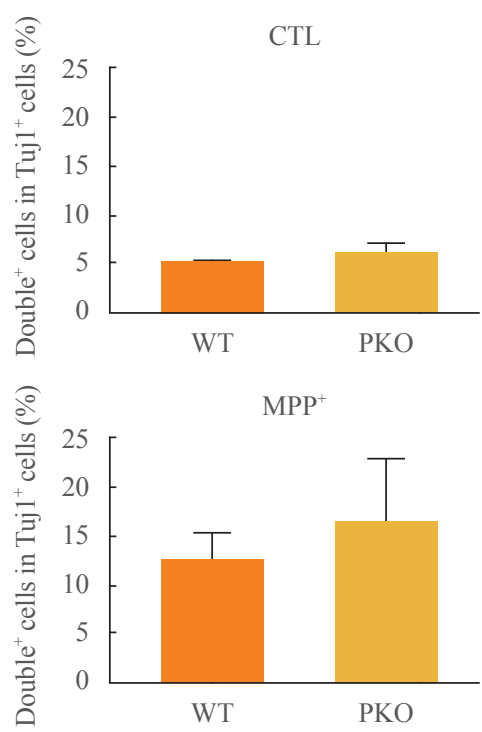

C

Fig. 3. Activity of caspase 3 in 1-methyl-4-phenylpyridinium (MPP ${ }^{+}$) treated wild-type (WT) and parkin knockout (PKO) neuronal cells. (A) Fluorescence-activated cell sorting analysis of WT and PKO cells treated with $1 \mathrm{mM} \mathrm{MPP}{ }^{+}$for 24 hours with anti-Tuj1 and antiactivated caspase 3 antibodies. Double ${ }^{+}$cells represent colabeling with Tuj1 and activated caspase 3 . The right panel shows the percentage of double $^{+}$cells per Tuj1 positive cells. (B) Western blot analysis of caspase 3 activity in WT and PKO cells. Cells were harvested 24 hours after $1 \mathrm{mM} \mathrm{MPP}^{+}$treatment and Western blot analysis was performed with an activated caspase 3 antibody. $\beta$-Actin was used as an internal control. (C) Immunocytochemistry of WT and PKO cells treated with $1 \mathrm{mM} \mathrm{MPP}^{+}$for 24 hours with anti-Tuj1 (green) and activated caspase 3 (red) antibody (scale bar, $20 \mu \mathrm{m}$ ). While $\mathrm{MPP}^{+}$treatment causes a significant increase in caspase 3 activity, no significant differences in caspase 3 activity are observed between WT and PKO neural cells. Data are expressed as the mean \pm SEM ( $n=3$ per group). Statistical analysis was performed by Student $t$ test. CTL, control without MPP ${ }^{+}$treatment; DAPI, 4, 6-diamidino-2-phenylindole. 
between WT and PKO cells (Fig. 1C).

\section{Cell death of PKO and WT neural cells by oxidative stress} To investigate the response of PKO neural cells against oxidative stress, $\mathrm{MPP}^{+}$, a metabolite of 1-methyl-4-phenyl-1, 2, 3, 6-tetrahydropyridine (MPTP), was treated with serial concentrations $(0,100,500,750,1,000,1,250$, and 1,500 $\mu \mathrm{M})$ after 15 days of differentiation for 24 hours. MTT assay showed that almost $60 \%$ of cells had died from $750 \mu \mathrm{M}$ to $1.5 \mathrm{mM}$ of $\mathrm{MPP}^{+}$treatment, and there were no significant differences in the profile of cell death between WT and PKO neural cells (Fig. 2).
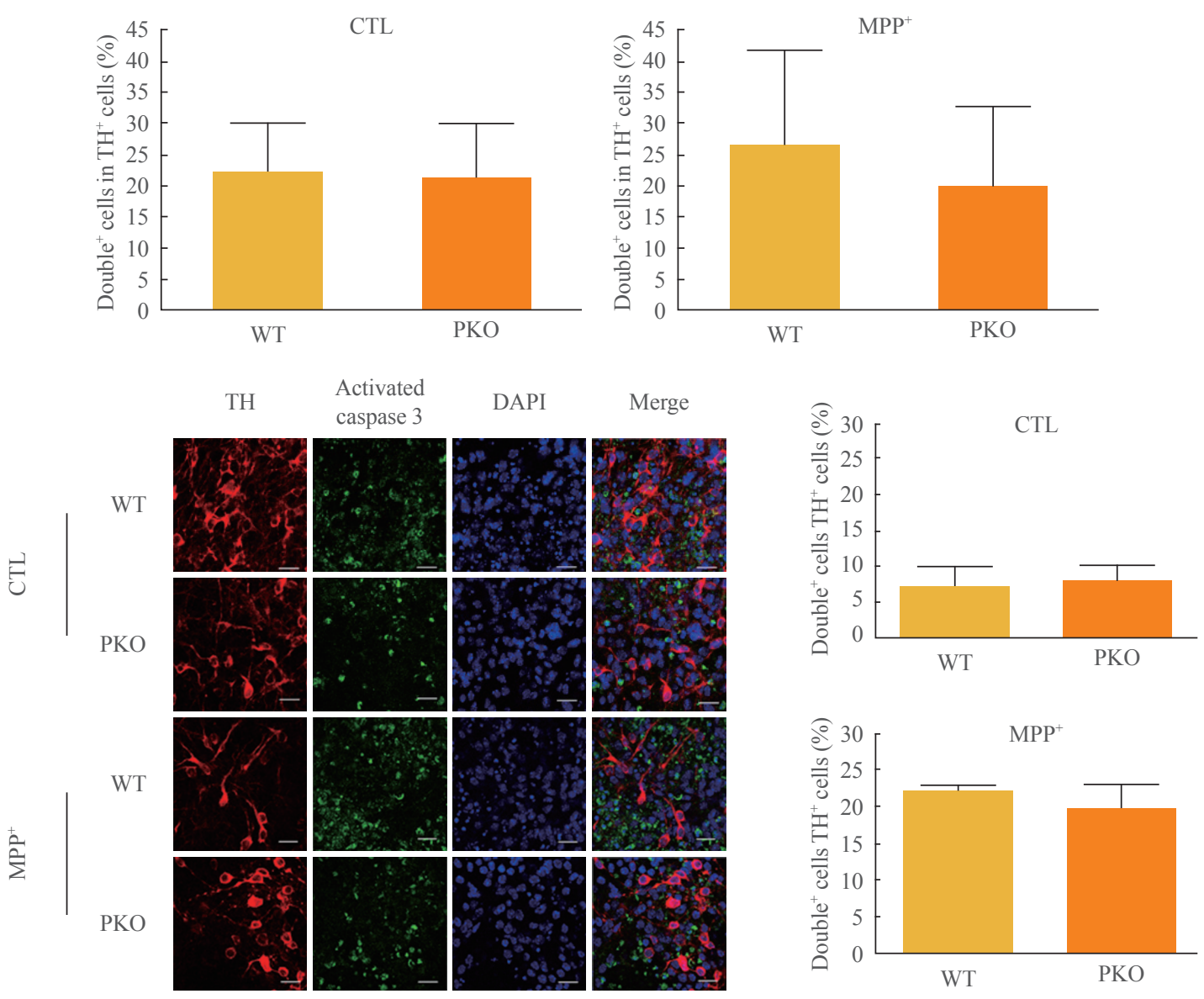

\section{oxidative stress}

To test whether $\mathrm{MPP}^{+}$-induced neuronal cell death is associated with apoptotic cell death, caspase 3 activity was determined with FACS analysis, Western blot analysis, and immunocytochemistry. Differentiated cells were treated with $1 \mathrm{mM} \mathrm{MPP}^{+}$, at which dose almost half of the cells died (Fig. 2); Tuj1 (a neural cell marker) and activated caspase 3 double positive cells were examined by FACS analysis. The Tuj1 and activated caspase 3 double positive cells were increased in $\mathrm{MPP}^{+}$treated groups by 3 -fold. However, there were no significant differences in $\mathrm{MPP}^{+}$-induced caspase 3-dependent apoptotic cell death between WT and PKO neural cells (Fig. 3A). Western blot analysis (Fig. 3B) and immunocytochemistry (Fig.

B

Fig. 4. Activity of caspase 3 in 1-methyl-4-phenylpyridinium $\left(\mathrm{MPP}^{+}\right)$treated wild-type (WT) and parkin knockout (PKO) dopaminergic neurons. (A) Fluorescence-activated cell sorting analysis of WT and PKO cells treated with $1 \mathrm{mM} \mathrm{MPP}{ }^{+}$for 24 hours with tyrosine hydroxylase (TH) and activated caspase 3 antibodies. Double ${ }^{+}$cells represent colabeling with TH and activated caspase 3 antibodies. Graphs show the percentage of double positive cells per TH-positive cells. (B) Immunocytochemistry of WT and PKO cells treated with $1 \mathrm{mM} \mathrm{MPP}^{+}$for 24 hours with TH (red) and activated caspase 3 (green) antibodies (scale bar, $20 \mu \mathrm{m}$ ). No significant differences in caspase 3 activity were observed between WT and PKO dopaminergic neurons. Data are expressed as mean \pm SEM ( $n=3$ per group). Statistical analysis was performed by Student $t$ test. CTL, control without MPP ${ }^{+}$treatment; DAPI, 4, 6-diamidino-2-phenylindole. 
3C) also showed no differences in $\mathrm{MPP}^{+}$-induced caspase 3-dependent apoptotic cell death between WT and PKO neural cells.

\section{Activation of caspase 3 in WT and PKO dopaminergic neurons by oxidative stress}

The sensitivity of PKO dopaminergic neurons against $\mathrm{MPP}^{+}-$ induced oxidative stress was examined by FACS analysis. Initially, the Tuj 1 and TH double positive cell population was examined. The double positive cell population represented about $20 \%$ of the Tuj1-positive cells (data not shown). After exposure to $1 \mathrm{mM} \mathrm{MPP}^{+}$, FACS analysis was performed with TH and activated caspase 3 antibodies. Double positive cells per TH-positive cells $(26.14 \% \pm 15.62 \%$ in WT cells and $19.81 \% \pm$ $12.75 \%$ in PKO cells) were similar in the two groups (Fig. 4A). Immunocytochemistry with TH and activated caspase 3 antibodies also showed a parallel result with the FACS analysis of the two groups (Fig. 4B).

\section{DISCUSSION}

It has been reported that Parkin, which is located in the cytoplasm or mitochondrial outer membrane, inhibits cell death induced by various stressors [14]. Most studies concerning the function of parkin against oxidative stress were performed in established cell lines, such as SH-SY5Y, PC12, and NM9D, which may not faithfully represent real conditions. To overcome these issues, PKO neural cells differentiated from PKO ES cells were used to examine the function of the parkin gene in cell death caused by oxidative stress. Consistent with the goals of our study, there were no differences in the neural differentiation efficiency between PKO and WT cells. This result was in accord with an in vivo study, which showed the number of TH-positive neurons were not different between WT and PKO mice [15].

As an oxidative stressor, $\mathrm{MPP}^{+}$, which is an active metabolite of MPTP, was used. MPTP is known to inhibit the mitochondrial complex 1 , and induce cellular oxidative stress $[16$, 17]. Previous studies suggest that $\mathrm{MPP}^{+}$is able to induce apoptotic cell death in vitro in various cell lines [18-21]. In this study, PKO neural cells showed no significant differences compared with WT cells against $\mathrm{MPP}^{+}$-induced oxidative stress as examined with MTT assay (Fig. 2) and caspase 3 activity-dependent apoptotic cell death (Figs. 3, 4). These results match with in vivo studies using PKO mice [22], and suggest that the parkin gene is not directly associated with cell death caused by $\mathrm{MPP}^{+}$-induced oxidative stress in neuronal cells differentiated from ES cells in vitro. However, these results differ from previous studies, which showed a protective role of parkin through ectopic over expression [23-26]. From these differences, it is apparent from this study that the protective function against oxidative stress is not a major component in the anticell death machinery.

This study analyzed the induced neural cells from ES cells. To exclude the possible contamination of other cell types differentiated from ES cells, we performed FACS analysis and immunocytochemistry to detect contamination at the single cell level. FACS analysis is based on cell population, hence a relatively small difference between groups is not easily distinguishable. Therefore, immunohistochemical marker analysis was carried out together. Immunocytochemistry data showed that more cells were activated caspase 3-positive in PKO cells after $\mathrm{MPP}^{+}$treatment (Figs. 3, 4).

In summary, PKO neuronal cells showed no significant difference in caspase 3-dependent cell death against $\mathrm{MPP}^{+}$-induced oxidative stress.

\section{CONFLICTS OF INTEREST}

No potential conflict of interest relevant to this article was reported.

\section{ACKNOWLEDGMENTS}

This research was supported by the Korea Research Foundation, funded by the Korean Government (Ministry of Education, Science and Technology) (Grant KRF-20120007428).

\section{REFERENCES}

1. Bossy-Wetzel E, Schwarzenbacher R, Lipton SA. Molecular pathways to neurodegeneration. Nat Med 2004;10 Suppl:S2-9.

2. Taylor JP, Hardy J, Fischbeck KH. Toxic proteins in neurodegenerative disease. Science 2002;296:1991-5.

3. Alam ZI, Jenner A, Daniel SE, Lees AJ, Cairns N, Marsden $\mathrm{CD}$, Jenner P, Halliwell B. Oxidative DNA damage in the parkinsonian brain: an apparent selective increase in 8-hydroxyguanine levels in substantia nigra. J Neurochem 1997; 69:1196-203.

4. Arlt S, Beisiegel U, Kontush A. Lipid peroxidation in neurodegeneration: new insights into Alzheimer's disease. 
Curr Opin Lipidol 2002;13:289-94.

5. Gabbita SP, Lovell MA, Markesbery WR. Increased nuclear DNA oxidation in the brain in Alzheimer's disease. J Neurochem 1998;71:2034-40.

6. Pedersen WA, Fu W, Keller JN, Markesbery WR, Appel S, Smith RG, Kasarskis E, Mattson MP. Protein modification by the lipid peroxidation product 4-hydroxynonenal in the spinal cords of amyotrophic lateral sclerosis patients. Ann Neurol 1998;44:819-24.

7. Finkel T, Holbrook NJ. Oxidants, oxidative stress and the biology of ageing. Nature 2000;408:239-47.

8. Shimura H, Hattori N, Kubo S, Mizuno Y, Asakawa S, Minoshima S, Shimizu N, Iwai K, Chiba T, Tanaka K, Suzuki T. Familial Parkinson disease gene product, parkin, is a ubiquitin-protein ligase. Nat Genet 2000;25:302-5.

9. Palacino JJ, Sagi D, Goldberg MS, Krauss S, Motz C, Wacker M, Klose J, Shen J. Mitochondrial dysfunction and oxidative damage in parkin-deficient mice. J Biol Chem 2004;279:18614-22.

10. Clark IE, Dodson MW, Jiang C, Cao JH, Huh JR, Seol JH, Yoo SJ, Hay BA, Guo M. Drosophila pink1 is required for mitochondrial function and interacts genetically with parkin. Nature 2006;441:1162-6.

11. Park J, Lee SB, Lee S, Kim Y, Song S, Kim S, Bae E, Kim J, Shong M, Kim JM, Chung J. Mitochondrial dysfunction in Drosophila PINK1 mutants is complemented by parkin. Nature 2006;441:1157-61.

12. Dodson MW, Guo M. Pink1, Parkin, DJ-1 and mitochondrial dysfunction in Parkinson's disease. Curr Opin Neurobiol 2007;17:331-7.

13. Ying QL, Stavridis M, Griffiths D, Li M, Smith A. Conversion of embryonic stem cells into neuroectodermal precursors in adherent monoculture. Nat Biotechnol 2003;21: 183-6.

14. Darios F, Corti O, Lucking CB, Hampe C, Muriel MP, Abbas N, Gu WJ, Hirsch EC, Rooney T, Ruberg M, Brice A. Parkin prevents mitochondrial swelling and cytochrome $\mathrm{c}$ release in mitochondria-dependent cell death. Hum Mol Genet 2003;12:517-26.

15. Goldberg MS, Fleming SM, Palacino JJ, Cepeda C, Lam HA, Bhatnagar A, Meloni EG, Wu N, Ackerson LC, Klapstein GJ, Gajendiran M, Roth BL, Chesselet MF, Maidment NT, Levine MS, Shen J. Parkin-deficient mice exhibit nigrostriatal deficits but not loss of dopaminergic neurons. J Biol Chem 2003;278:43628-35.
16. Langston JW, Ballard P, Tetrud JW, Irwin I. Chronic Parkinsonism in humans due to a product of meperidine-analog synthesis. Science 1983;219:979-80.

17. Schapira AH, Cooper JM, Dexter D, Jenner P, Clark JB, Marsden CD. Mitochondrial complex I deficiency in Parkinson's disease. Lancet 1989;1:1269.

18. Dipasquale B, Marini AM, Youle RJ. Apoptosis and DNA degradation induced by 1-methyl-4-phenylpyridinium in neurons. Biochem Biophys Res Commun 1991;181:1442-8.

19. Du Y, Dodel RC, Bales KR, Jemmerson R, Hamilton-Byrd E, Paul SM. Involvement of a caspase-3-like cysteine protease in 1-methyl-4-phenylpyridinium-mediated apoptosis of cultured cerebellar granule neurons. J Neurochem 1997; 69:1382-8.

20. Hartley A, Stone JM, Heron C, Cooper JM, Schapira AH. Complex I inhibitors induce dose-dependent apoptosis in PC12 cells: relevance to Parkinson's disease. J Neurochem 1994;63:1987-90.

21. Itano Y, Nomura Y. 1-methyl-4-phenyl-pyridinium ion $\left(\mathrm{MPP}^{+}\right)$causes DNA fragmentation and increases the Bcl-2 expression in human neuroblastoma, SH-SY5Y cells, through different mechanisms. Brain Res 1995;704:240-45.

22. Thomas B, von Coelln R, Mandir AS, Trinkaus DB, Farah MH, Leong Lim K, Calingasan NY, Flint Beal M, Dawson VL, Dawson TM. MPTP and DSP-4 susceptibility of substantia nigra and locus coeruleus catecholaminergic neurons in mice is independent of parkin activity. Neurobiol Dis 2007;26:312-22.

23. Fallon L, Belanger CM, Corera AT, Kontogiannea M, Regan-Klapisz E, Moreau F, Voortman J, Haber M, Rouleau G, Thorarinsdottir T, Brice A, van Bergen En Henegouwen $\mathrm{PM}$, Fon EA. A regulated interaction with the UIM protein Eps15 implicates parkin in EGF receptor trafficking and PI(3)K-Akt signalling. Nat Cell Biol 2006;8:834-42.

24. Henn IH, Bouman L, Schlehe JS, Schlierf A, Schramm JE, Wegener E, Nakaso K, Culmsee C, Berninger B, Krappmann D, Tatzelt J, Winklhofer KF. Parkin mediates neuroprotection through activation of IkappaB kinase/nuclear factorkappaB signaling. J Neurosci 2007;27:1868-78.

25. Jiang H, Jiang Q, Feng J. Parkin increases dopamine uptake by enhancing the cell surface expression of dopamine transporter. J Biol Chem 2004;279:54380-6.

26. Jiang H, Ren Y, Zhao J, Feng J. Parkin protects human dopaminergic neuroblastoma cells against dopamine-induced apoptosis. Hum Mol Genet 2004;13:1745-54. 